\title{
El rol de los sectores indígenas en la independencia del Perú. Bases para una nueva interpretación
}

\author{
por \\ Silvia Escanilla Huerta ${ }^{1}$ \\ University of Illinois at Urbana-Champaign
}

\begin{abstract}
El rol de los sectores indígenas en el proceso de independencia del Perú nunca ha sido del todo claro. Para algunos historiadores los sectores indigenas no tuvieron mayor participación en el proceso, pero para otros los sectores indigenas fueron los auténticos patriotas cuya inalterable lealtad a la causa de la independencia se contrapuso a la actitud dubitativa exhibida por las elites entre 1808 y 1824. Dado que los sectores indígenas constituían la mayoría de la sociedad virreinal y que participaron activamente como soldados en la guerra de independencia, este artículo propone avanzar más allá de posturas dicotómicas para analizar a los sectores indigenas como destacados actores politicos del periodo. A partir de la exploración de las estrategias políticas que los sectores indígenas desplegaron desde el comienzo de la crisis monárquica en 1808 y hasta el fin de la guerra en 1824 se propone que los sectores indigenas inauguraron una nueva manera de hacer política que definiría la guerra y que perduraría mucho después de la independencia.
\end{abstract}

PalabRAS Clave: sectores indigenas; guerra de independencia; guerrillas; virreinato del Perú.

Cómo citar este artículo / Citation: Escanilla Huerta, Silvia, "El rol de los sectores indígenas en la independencia del Perú. Bases para una nueva interpretación", Revista de Indias, LXXXI/281 (Madrid, 2021): 51-81. https://doi.org/10.3989/revindias.2021.002.

* Dedico este artículo a mi hijo Lucas Trejo Kosovych quien llegó al mundo cuando su madre se afanaba escribiendo estas líneas y muy graciosamente permitió que lo terminara durante sus primeras semanas de vida. Agradezco a Natalia Sobrevilla Perea su apoyo, sin el cual estas líneas no hubieran visto la luz.

1 escanil2@illinois.edu, ORCID iD: https://orcid.org/0000-0001-7196-9490 de uso y distribución Creative Commons Reconocimiento 4.0 Internacional (CC BY 4.0). 
La invasión napoleónica a España en 1808 generó una profunda crisis en el imperio español. La vacatio regis creó un dilema de representación que las ciudades españolas resolvieron con la creación de juntas de gobierno en nombre de Fernando VII de acuerdo con la tradición pactista ${ }^{2}$. Varias ciudades americanas siguieron el ejemplo de las españolas y organizaron sus propias juntas de gobierno, pero al hacerlo no solo cuestionaron la legitimidad de los virreyes y funcionarios reales locales sino también la autoridad de las juntas peninsulares sobre los territorios americanos ${ }^{3}$. La creación de juntas de gobierno autónomas en américa profundizó la crisis política del imperio y amenazó con desintegrarlo ${ }^{4}$.

En este contexto de crisis, solo las capitales virreinales de México y Perú se mantuvieron leales a la corona española durante la década de 1810. En el caso del Perú, una vasta historiografía ha procurado por años explicar este hecho dado que como Natalia Sobrevilla ha notado, una característica distintiva del proceso de independencia en el Perú es la dificultad para encontrar «héroes nacionales» ${ }^{5}$. La más reciente historiografía sostiene que la coincidencia de intereses entre la elite limeña y la corona española explica el fidelismo de éstas y su financiamiento del bando realista durante la guerra ${ }^{6}$. Asimismo, los historiadores han resaltado la figura del virrey Abascal y su habilidad política para mantener el virreinato bajo control español ${ }^{7}$. Por estos motivos, el virreinato del Perú es caracterizado como un centro contrarrevolucionario que solo comenzó a desmoronarse cuando la expedición libertadora a cargo de José de San Martín arribó a Paracas en septiembre de 1820. Los sectores criollos que en otros espacios americanos lideraron el proceso de ruptura con la metrópoli, en el Perú habrían dependido de ayuda externa para lograr la independencia.

Respecto de los sectores populares existe un problema similar dado que hubo quienes apoyaron a los realistas mientras otros apoyaron a los independentistas y los cambios de bando fueron muy frecuentes. Por ello, Alberto Flores Galindo señaló en un famoso libro que no existió una voluntad general o una acción coordinada por parte de los sectores populares que hubiese podido quebrar el dominio español en el Perú. En este sentido, para los histo-

\footnotetext{
2 Chiaramonte, 2003.

${ }^{3}$ Quijada, 2005.

${ }^{4}$ Guerra, 1993.

${ }^{5}$ Sobrevilla Perea, 2015: 400.

${ }^{6}$ Mazzeo, 2018.

7 Un reciente ejemplo en O’Phelan Godoy y Lomné, 2013. También Peralta, 2002.Vargas Ezquerra, 2010.

${ }^{8}$ Flores Galindo, 1991.
} 
riadores en el Perú las rebeliones que ocurrieron durante la década de 1810 fueron fallidas porque sus líderes no tuvieron un proyecto político que incluyera a varios sectores sociales y/o no lograron sostener alianzas políticas perdurables en el tiempo'. A pesar de que en los últimos años se han producido varios estudios de caso, lo que Alberto Flores Galindo propusiera hace más de veinte años, continua vigente ya que no se ha producido una narrativa que intente comprender las características que tuvo la participación de los sectores populares en la independencia. Esto va a contramano de lo ocurrido en Latinoamérica ya que en los últimos veinte años se ha producido una renovación historiográfica en la que el papel de los sectores populares en la independencia toma un rol preponderante. De hecho, Gabriel Di Meglio ha señalado que no se puede comprender la independencia si no se tiene en cuenta el rol que los sectores populares jugaron en el proceso ${ }^{10}$. Por este motivo, la propuesta del Perú como un centro contrarrevolucionario resulta incompleta en tanto no explica el rol que las rebeliones de la década de 1810 tuvieron en el proceso, así como tampoco explica la intervención de los sectores populares en este periodo. Asimismo, Juan Marchena Fernández ha señalado acertadamente que el rol que le cupo a la mayor parte de la población del virreinato del Perú «no ha sido desarrollada con la extensión, profundidad e intensidad que el tema amerita y requiere ${ }^{11}$. Por ello, siguiendo la recomendación de Marchena Fernández, en este articulo la propuesta es primero ofrecer un balance historiográfico centrado en el comportamiento de los sectores indígenas durante el proceso de independencia en el Perú. Luego, teniendo en cuenta el estado actual de las investigaciones, se postula que existen bases suficientes para proponer una nueva perspectiva del rol de los sectores indígenas en la independencia. Partiendo del análisis de un caso específico a modo de ejemplo, esta nueva perspectiva evade posturas dicotómicas ya obsoletas (ifueron patriotas o no lo fueron?) a la vez que procura centrarse en comprender la lógica y los cambios de las prácticas políticas de los sectores indígenas en este periodo. En última instancia, la propuesta aspira a concebir de manera más amplia y multifacética el proceso de independencia del Perú entendiéndolo como un proceso histórico contingente que no tuvo un único significado o connotación para quienes lo protagonizaron ${ }^{12}$. De esta forma, recuperando el sentido que la experiencia tuvo para sus actores se

\footnotetext{
9 O'Phelan Godoy, 1987.

10 Di Meglio, 2013: 98.

11 Marchena Fernández, 2017: 27.

12 Serulnikov, 2010a.
} 
vislumbra una nueva narrativa de la independencia del Perú mucho más diversa e incluyente que las precedentes.

\section{UN VIEJO PROBLEMA}

Para aquellos que escribieron las primeras historias de la independencia del Perú a mediados del siglo XIX, los sectores indígenas no ocuparon ningún rol en el proceso o este fue mínimo porque estos autores prefirieron exaltar en cambio a los sectores criollos cuyos líderes denominaron precursores de la independencia ${ }^{13}$. Los sectores indígenas fueron mencionados en ciertas ocasiones, pero su rol fue minimizado debido a que según estos autores la movilización indígena aún se anclaba en el drama de la conquista de américa ${ }^{14}$. La exaltación de los denominados padres de la patria en el logro de la independencia peruana continuó durante el siglo XX, consolidando así una narrativa que promovió la imagen de un pueblo peruano unido en su oposición a la tiranía hispánica ${ }^{15}$. Esta perspectiva llevó a José Agustín de la Puente Candamo a postular la noción de un «Perú mestizo» ${ }^{16}$. En este y otros casos, las historias sobre la independencia peruana pusieron a la «nación peruana» en el origen del proceso de ruptura con España dado que ya en 1820 esta nación había alcanzado la madurez política necesaria para conseguir la independencia. En este sentido la guerra de independencia se presentó como un enfrentamiento entre el «pueblo peruano» y los realistas a pesar de que «el pueblo peruano» de las narrativas solo incluía a los sectores aristocráticos criollos ${ }^{17}$.

Un cambio en esta perspectiva se produjo en paralelo con los festejos por el sesquicentenario de la independencia. El gobierno dictatorial del general Velasco Alvarado encargó a la Comisión Nacional del Sesquicentenario de la

13 Véase Pruvonena, 1858, tomo 1. Torrente, 1829, tomo 1. Paz Soldán, 1868, vol. 1.

${ }^{14}$ Esto llevó a Benjamín Vicuña Mackenna a subrayar el rol de los hermanos Angulo en la revolución del Cuzco llamada «revolución de Pumacahua». Sobre el polémico lugar de este historiador chileno en la historiografía peruana véase Peralta Ruíz, 2013.

15 Autores posteriores a Vicuña Mackenna, Paz Soldán y Mariátegui se encargaron de ampliar y consolidar la genealogía de precursores de la independencia, incorporando rebeliones previas a 1821. Véase Basadre, 1929-30, tomo 1.

${ }^{16}$ La idea de mestizaje social implicaba una subsunción de las diferencias sociales bajo la idea de patria nacional. Véase De la Puente Candamo, 1971: 145 y ss.

${ }^{17}$ De la Puente Cándamo, 1971: 21. Ejemplos de esta tradición historiográfica son: Vargas Ugarte, 1958. Leguía y Martínez, 1921 Germán Leguía y Martínez, “Los guerrilleros peruanos", La Prensa, Lima, 1921. Basadre, 1929. Morán, 2011. Un análisis sobre las razones políticas por las que la historiografía decimonónica peruana optó por esta interpretación, en Earle, 2008. 
independencia del Perú la edición de la Colección documental de la independencia del Perú18. Esta Colección, la cual comprendió un arduo trabajo de recopilación de fuentes primarias apuntaba a consolidar la idea de una épica del pueblo peruano en pos de su liberación del dominio español, liberación que había quedado incompleta y que ahora el gobierno impulsaba ${ }^{19}$. En este marco la Colección incluyó la rebelión de Túpac Amaru y el gobierno hizo del líder indígena un precursor de la independencia peruana y un símbolo del gobierno y la reforma agraria que proponía ${ }^{20}$. Asimismo, otros volúmenes de la Colección apostaron con pruebas documentales a sostener la idea de que los sectores indígenas habían sido los verdaderos patriotas del proceso, quienes encarnaban al verdadero «pueblo» que luchó en la guerra de independencia tal como el tomo cinco La acción patriótica del pueblo en la emancipación. Guerrillas y montoneras, lo indica ${ }^{21}$.

La instalación de los sectores indígenas como protagonistas y héroes de la independencia desde una perspectiva nacionalista tuvo larga y fructífera vida ya que numerosos autores produjeron estudios detallados sobre la participación patriótica de los sectores indígenas en la independencia. Gustavo Vergara Arias y Ezequiel Beltrán Gallardo centraron sus estudios en las guerrillas indígenas siguiendo los pasos de Raúl Rivera Serna. Este ya había analizado el accionar de las guerrillas en la sierra central entre los años 18211825 , partiendo de «la reiterada manifestación de su orgullo nacional» y su «finalidad orientada al logro de nuestra independencia»"2 . Para este autor, las guerrillas habrían sido una pieza fundamental en la estrategia patriota para vencer a los realistas, no solo por su ubicación geográfica, sino por su apoyo económico y logístico, además del bélico ${ }^{23}$.

En esta misma senda, Ezequiel Beltrán Gallardo estudió a los guerrilleros de la provincia de Yauyos, destacando la importancia de las campañas del general Álvarez de Arenales en la sierra para impulsar «el fervor patriótico que les caracterizaba» y el heroísmo y coraje de los yauyinos quienes «se presentaban henchidos de entusiasmo, pletóricos de fervor patriótico y

${ }_{18}$ Comisión nacional del Sesquicentenario..., 1971-1976.

19 Aguirre, 2018.

20 Túpac Amaru fue incluido en el tomo 2 de la Colección Documental de la Independencia de Perú (Comisión Nacional del Sesquicentenario..., 1971-1976), pero también se publicó en la Colección documental del bicentenario (Comisión del Bicentenario de la Rebelión Emancipadora de Tupac..., 1980). Véase Walker, 2018.

${ }^{21}$ Una lista de los tomos en Contreras, 2007:101-104.

${ }^{22}$ Rivera Serna, 1958: 132-133.

${ }^{23}$ Ibidem: 127, 133. 
listos a empuñar el fusil para defender la libertad de sus pueblos ${ }^{24}$. Gustavo Vergara Arias, por su parte, analizó con detenimiento la formación de guerrillas y montoneras, dividiéndolas en dos tipos: montoneras y partidas de guerrillas ${ }^{25}$. Para Vergara Arias, las guerrillas representaron «la manifestación más clara del espíritu de rebeldía del hombre peruano», por el apoyo que brindaron en todo momento los pueblos, tanto en hombres como en víveres e incluso dinero a la «sagrada causa de la patria» ${ }^{26}$. Su contribución fundamental, según Vergara Arias, fue el debilitamiento de la estructura de dominación de los realistas, lo cual les asignaría un papel clave en la independencia peruana.

Ya en la década de 1980 esta línea de pensamiento continuó con autores como Virgilio Roel Pineda quien enfatizó la decidida participación indígena en las guerrillas, acentuando a su vez el papel «traidor» tanto de los criollos ricos como de los extranjeros San Martin y Bolívar. Roel Pineda distinguió a los criollos en dos grupos, ricos y pobres y resaltó el heroísmo y la valentía de los indígenas, verdaderos olvidados por la historia ${ }^{27}$. Así, insertó «el ingrediente de las clases sociales» añadiendo además que «el nacionalismo» era patrimonio exclusivo de «los de abajo ${ }^{28}$. Otros autores han continuado esta visión nacionalista, sobre todo en regiones donde la participación de los sectores populares en la guerra de independencia ha recibido más atención que en $\operatorname{Lima}^{29}$.

La postura nacionalista que presenta a los sectores indígenas como patriotas obtuvo una contundente desmentida con la aparición en 1972 del artículo de Heraclio Bonilla y Karen Spalding, "La independencia en el Perú: las palabras y los hechos", que inauguró no solo una corriente revisionista sino también una encendida polémica que perduró varias décadas ${ }^{30}$. La denominada visión desencantada propuesta por Bonilla y Spalding planteaba que la independencia había sido un mero cambio político que no había modificado las estructuras de dominación económica y social. Por ello, la independencia no había sido conseguida sino concedida porque las elites habían sido fieles a España hasta que la independencia apareció como un hecho inevitable al que se resignaron. Asimismo, destacaba que los sectores indígenas habían

24 Beltrán Gallardo, 1977: 15.

${ }^{25}$ La diferencia fundamental está dada por la falta de organización formal de la primera respecto de la segunda. Vergara Arias, 1973: 30-32.

26 Ibidem: 193.

27 Roel Pineda, 1988: 13.

28 Contreras, 2007: 105.

29 Cabe destacar a Rosas Cuadros, 1971; 1976. También a Ipinze, 2005; 2010.

${ }^{30}$ Bonilla y Spalding, 1972. 
asistido pasivos y en silencio al desenlace de la guerra ${ }^{31}$. Si bien posteriormente Bonilla analizó la participación popular a partir de la conformación de guerrillas y montoneras en el contexto de la guerra, de todas maneras sostuvo que la oposición de los pueblos a la causa de la independencia había sido mucho más determinante ${ }^{32}$. Bonilla destacó que, aunque era innegable la presencia indígena tanto en los ejércitos patriotas como en los realistas, su participación «no obedece a intereses que les sean directamente sustantivos»»"

La línea de pensamiento revisionista inaugurada por Bonilla fue continuada por otros historiadores quienes cuestionaron la versión nacionalista y sobre todo el énfasis en la «voluntad general» por obtener la independencia. Timothy Anna por ejemplo afirmó que «los peruanos no habían optado por ser independientes ${ }^{34}$. Prácticamente no se refirió a la participación popular excepto para mencionar su inacción en la capital ${ }^{35}$. Respecto de las guerrillas, las caracterizó como «bandoleros armados», subrayando su indisciplina y la dificultad para distinguirlos de los criminales comunes ${ }^{36}$. John Fisher por su parte sostuvo que la actividad guerrillera en el valle del Mantaro estuvo protagonizada por «grupos de desarraigados» antes que por comunidades organizadas $^{37}$. John Lynch también entendió que las «bandas guerrilleras que operaron en el centro del Perú entre 1821 y 1824 no eran fuerzas irregulares indias o populistas. Eran criollos y mestizos de clase media y modesta fortuna, cuyas propiedades y familias habían sufrido a manos de los realistas y que buscaban venganza» ${ }^{38}$. En este sentido, enfatizó el reclutamiento forzoso, la falta de apoyo popular y los frecuentes episodios de pillaje en los que se vieron involucradas. Asimismo, puso de relieve las desavenencias entre los jefes guerrilleros que no permitieron que hicieran «una contribución decisiva» a la causa independentista ${ }^{39}$.

La visión revisionista encontró oposición en historiadores como Jorge Basadre quien planteó que, si bien faltaban estudios sobre la participación popular, no se podía negar que esta hubiera existido ${ }^{40}$. Con el mismo espíritu,

31 «El hecho fundamental es este gran silencio de las masas populares del Perú: su no participación en el proceso de la independencia...», Bonilla y Spalding, 1972: 43.

32 Bonilla, 2001: 69.

33 Ibidem: 118.

${ }^{34}$ Anna, 2003: 253.

35 Ibidem: 71.

36 Ibidem: 238-287.

37 Fisher, 2000: 175-198.

38 Lynch, 1980: 182.

39 Ibidem: 183.

40 Basadre, 1973. 
historiadores como John Fisher, Luis Miguel Glave y Scarlett O'Phelan Godoy destacaron las rebeliones ocurridas durante el temprano siglo XIX (en las cuales los sectores indígenas participaron) incluyéndolas en la genealogía de la movilización social a nivel regional en contra de los intereses concentrados en Lima ${ }^{41}$.

La división entre los defensores de la independencia concedida y aquellos que sostuvieron que la independencia había sido conseguida se mantuvo por varias décadas. Sin embargo, en los últimos años numerosos historiadores procuraron zanjar esta dicotomía ofreciendo interpretaciones más complejas de los eventos que forman parte del proceso independentista peruano, en particular respecto de los sectores indígenas. Christine Hünefeldt y Nuria Sala i Vila cuentan con una larga lista de publicaciones que analizan los conflictos que las comunidades indígenas protagonizaron luego de la rebelión de Túpac Amaru y hasta $1815^{42}$. Las investigaciones de David Cahill, David Garrett y Margareth Najarro se han centrado tanto en la nobleza indígena como en los indios del común antes, durante y después de la revolución del $\mathrm{Cuzco}^{43}$. Más recientemente Natalia Sobrevilla y Cecilia Méndez han analizado momentos específicos de la guerra de independencia poniendo el foco en las milicias indígenas tanto patriotas como realistas ${ }^{44}$. A pesar de ello, como ha expresado Luis Miguel Glave en una reciente publicación, una propuesta historiográfica que avance una nueva interpretación de la independencia ya alejada de esta dicotomía es aún una tarea pendiente ${ }^{45}$.

Desde una perspectiva latinoamericana, la falta de renovación en la narrativa de la independencia peruana se destaca porque la historiografía sobre la independencia en América Latina en las últimas décadas ha abandonado las posturas nacionalistas y las versiones triunfalistas de este proceso. En su lugar abundan los estudios que exploran las motivaciones que diversos sectores tuvieron para apoyar o rechazar proyectos separatistas durante la década de 1810. En ese contexto se ha revalorizado el papel de los sectores populares destacando como la heterogeneidad de intereses y la existencia de múltiples proyectos políticos divergentes fueron común denominador, así

\footnotetext{
${ }^{41}$ Fisher, 1979. O'Phelan Godoy, 1987; 1988; 1997; 2009. Glave 2002; 2005; 2013.

${ }_{42}$ Hünefeldt, 1982. Sala i Vila, 1991; 1996.

${ }^{43}$ Cahill, 1984. Cahill y O'Phelan Godoy, 1992. Garrett, 2009. Najarro, 2017.

${ }_{44}$ Sobrevilla, 2011; 2012. Méndez, 2014.

45 Glave, 2015: 20.
} 
como también la noción de que se avecinaba un nuevo tiempo para los habitantes del imperio ${ }^{46}$.

En este sentido, lo que se propone aquí es sumarse a esta nueva historiografía a partir del análisis de los sectores indígenas partiendo de dos premisas. La primera, que los sectores indígenas no constituyeron un movimiento homogéneo sino una multitud de comunidades con identidades específicas y circunscriptas a dinámicas locales y regionales, las cuales en oportunidades incluyeron mestizos, negros y españoles, aunque no siempre ni en todos los $\operatorname{casos}^{47}$. La segunda, que durante la década de 1810 los sectores indígenas fueron activos participantes en la guerra de independencia. Hubo comunidades apoyando al bando realista, comunidades apoyando al bando llamado insurgente y comunidades manteniendo una distancia neutral en aquellos casos en que esto fue posible. En todos los casos, la forma en la que se insertaron en la guerra de independencia fue específica para el virreinato del Perú porque respondió a dinámicas políticas locales, así como también a consideraciones logísticas y tácticas. La propuesta historiográfica postula que los sectores indígenas participaron activamente de la guerra de independencia a través de la guerrilla, la cual emergió como la estrategia política y militar elegida por muchas comunidades indígenas para impulsar sus intereses de corto y largo plazo. Una narrativa de la independencia que contemple el análisis de las guerrillas indígenas como eje conductor permite articular el proceso de movilización social indígena en el largo siglo XVIII con las luchas del siglo XIX. Asimismo, dada la persistencia de la guerrilla luego de la independencia, poner esta forma política en el centro del análisis puede potencialmente transformar nuestra comprensión no solo del proceso independentista en el virreinato del Perú sino del Perú del siglo XIX.

\section{UNA NUEVA MIRADA}

Los sectores indígenas constituyeron la mayor parte de la población del virreinato del Perú durante sus tres siglos de existencia. A pesar de ello, su

46 Di Meglio, 2013, ha señalado que la idea de independencia no figuró entre las principales preocupaciones de muchos de los insurgentes a lo largo del territorio americano.

${ }_{47}$ Ello lleva a establecer qué se entiende en este artículo por «sectores indígenas». Sigo aquí la definición propuesta por Díaz, 2017, que identifica como «indígena» a una identidad local suscripta a una comunidad especifica definida por marcadores étnicos y prácticas culturales desarrollados en los Andes. En este caso me centro en comunidades que se identificaban legalmente como «indios» (este es el caso de Huacho) aunque su población fuese más o menos diversa. 
estudio siempre ha sido una tarea dificultosa en la que abundan análisis de fenómenos locales que si bien son muy necesarios no han logrado esbozar una teoría general sobre su rol en el proceso independentista ${ }^{48}$. La carencia de una mirada de conjunto resulta en primer lugar de la dispersión de los archivos en los cuales se podrían localizar pistas sobre la participación indígena en la independencia ${ }^{49}$. En relación con ello, el estado de conservación de muchos documentos es precario y la información que contienen es meramente fragmentaria. Por este motivo, es necesario generar un volumen significativo de estudios realizados en condiciones similares y bajo las mismas premisas para comprobar ciertas hipótesis. Finalmente, dado que la mayoría de los documentos disponibles han sido producidos por terceros, ya sean oficiales de la corona o funcionarios regionales, es una tarea cuanto menos indiciaria el establecer las motivaciones que los sectores indígenas pudieron haber tenido para participar del proceso que desembocó en la independencia del Perú ${ }^{50}$. A pesar de estas limitaciones existe una cantidad suficiente de estudios sobre los sectores indígenas como para afirmar sin lugar a duda que su participación en el proceso independentista fue muy significativa. Esta afirmación se ancla en una serie de postulados que basados en las investigaciones actuales permiten proponer una nueva narrativa de la independencia. Los postulados son los siguientes:

1) La movilización indígena continuó luego de la rebelión de Túpac Ama$r u$. La historiografía sobre la rebelión ha planteado que esta rebelión cerró el ciclo de rebeliones indígenas que se multiplicaron durante el siglo XVIII ${ }^{51}$. Estas rebeliones tuvieron múltiples causas, pero se basaron fundamentalmente en la presión tributaria que la existencia del reparto sumado a la indiscriminada apropiación de tierras generó en las comunidades indígenas. Luego de que la rebelión de Túpac Amaru y las de Túpac Katari y Tomas Katari fueran derrotadas, la corona impulsó campañas «de pacificación» que procuraron eliminar toda disidencia en particular en la zona del Cuzco. Asimismo, la corona impulsó nuevas medidas en el contexto de las reformas borbónicas

48 Para mencionar solo algunos: Cáceres-Olazo Monroy, 1999. Espinoza Soriano, 2007. Igue, 2008. Sánchez Jara, 2010. Adanaqué Velásquez, 2010. Mendoza Villanueva, 2012. Rosado Loarte, 2017.

${ }^{49}$ Los documentos se hayan dispersos en numerosos archivos regionales peruanos además de los que se hayan en la capital del Perú. También deben considerarse el Archivo Histórico de La Paz (La Paz, Bolivia), el Archivo Nacional de Bolivia (Sucre, Bolivia), el Archivo General de la Nación (Buenos Aires, Argentina); el Archivo Histórico Nacional (Madrid, España) y el Archivo General de Indias, Sevilla (España).

${ }^{50}$ La expresión «indiciario» se refiere al método descrito y analizado por Ginzburg, 1999.

${ }^{51}$ O’Phelan Godoy, 1988. Walker, 2014. Serulnikov, 2006; 2010 b. 
con el objetivo de responder y mitigar los reclamos. Con la abolición del reparto y la figura del kuraka en franca decadencia, los historiadores plantearon que había llegado a su fin el ciclo de insurrección andina. Sin embargo, nuevas investigaciones sugieren que esta movilización no se detuvo, sino que persistió a pesar de la implementación de las reformas borbónicas, e incluso fue instigada por ellas ${ }^{52}$. Por ejemplo, Christine Hünefeldt y más recientemente David Klassen han propuesto que la resistencia al tributo representó un desafío abierto a la autoridad de la corona española, el cual abrió la puerta a la construcción de autoridades paralelas durante la década de $1810^{53}$. Asimismo, la movilización indígena no fue solo una reacción a políticas globales y practicas locales de la corona española, sino también el producto de cambios al interior de las comunidades indígenas que persistieron luego de la rebelión de Túpac Amaru tal como Scarlett O'Phelan planteara hace ya veinte años ${ }^{54}$. Estas investigaciones ponen de manifiesto que el proceso de desgaste de la autoridad imperial con respecto a las comunidades indígenas tuvo largo aliento y no se detuvo con la masiva represión ejecutada por la corona. Si bien las rebeliones analizadas por estos autores tuvieron carácter localizado y variada suerte, su existencia demuestra que una parte significativa de la población del virreinato continuó pujando por cambios en su relación con la corona a pesar de la derrota del proyecto tupamarista. En este sentido, no se trata aquí de postular a Tupac Amaru como un precursor de la independencia sino más bien de insertar el proceso independentista en un contexto de crisis de larga duración de la relación entre la corona española y las comunidades indígenas ${ }^{55}$. De la misma manera, la vacatio regis no habría sido «un rayo en un cielo despejado» sino «una antorcha caída sobre pasto seco» lo cual no minimiza el impacto de este cambio político sino más bien lo presenta como un acontecimiento sumamente disruptivo en el contexto de una relación colonial ya desgastada ${ }^{56}$.

2) Durante la crisis imperial de 1808 el apoyo indígena fue fundamental tanto en la formación de juntas de gobierno como en su sofocamiento. La historiografía peruana suele ignorar la formación de juntas en 1809 debido a que ocurrieron en lo que actualmente es Bolivia. Si bien es cierto que en 1809 ni Chuquisaca ni La Paz pertenecían al virreinato del Perú pues ambas habían sido transferidas al recién creado virreinato del Río de la Plata en 1776, la

\footnotetext{
52 O’Phelan Godoy, 1987. Sala i Vila, 1996.

53 Hünefeldt, 1982. Klassen, 2016.

54 O’Phelan Godoy, 1997. Maqque, 2015.

55 Continúa siendo indispensable en este contexto, Thomson, 2002. Serulnikov, 2006.

56 La expresión ha sido tomada de Di Meglio, 2013: 98
} 
región del alto Perú había pertenecido a este virreinato desde la conquista. Más allá de límites geopolíticos, no cabe duda de que el alto y el bajo Perú tenían lazos económicos, sociales y culturales que hacían de la región, una y la misma ${ }^{57}$. Cuando estalló la insurrección, Buenos Aires se hallaba en pleno proceso de transferencia de mando entre el virrey Liniers y el nuevo virrey Cisneros. Esta circunstancia, sumada al pedido de auxilio del gobernador intendente de Potosí, Francisco de Paula Sanz, llevó al virrey Abascal a solicitar al presidente de la audiencia del Cuzco, José Manuel de Goyeneche, que organizara una expedición militar destinada a acabar con la sublevación ${ }^{58}$. Este creó un contingente de 5000 milicianos provenientes de Cuzco, Arequipa y Puno a los que se ocupó de entrenar personalmente. Asimismo, contó con el apoyo de los kurakas Mateo Pumacahua de Cuzco y José Domingo Choquehuanca, de Azángaro, que enviaron sus regimientos ${ }^{59}$. Fueron ellos quienes aplastaron a las fuerzas revolucionarias antes de que el contingente militar enviado desde Buenos Aires arribara a destino en diciembre de 1809. Tanto Pumacahua como Choquehuanca habían resistido exitosamente los desafíos a su autoridad a nivel local y eran poderosos terratenientes cuyos intereses habían sido protegidos por funcionarios coloniales ${ }^{60}$. Desde ese lugar, en el contexto de crisis de autoridad que la vacatio regis había generado ellos eligieron sostener las jerarquías tradicionales del poder dado que formaban parte de ellas ${ }^{61}$. Su posición era diferente y de alguna manera excepcional respecto de otros kurakas indígenas quienes interpretaron la coyuntura como una oportunidad para rechazar la imposición de caciques foráneos para el cobro del tributo entre otras medidas ${ }^{62}$.

A pesar de que fue derrotada, la movilización indígena encontró nuevo aliento luego de la revolución de mayo de 1810 en Buenos Aires, con el envío del llamado Ejército del Norte o Ejercito Auxiliar del Perú. Este reactivó las redes de comunicación indígena y la organización de grupos insurgentes que colaboraron abiertamente con el ejército comandado por Juan José Castelli. Específicamente, en Cochabamba se produjo un movimiento en el cual los líderes juraron fidelidad a la junta de Buenos Aires luego de lo cual actuaron en coordinación con las milicias indígenas de Juan Manuel de Cáceres, quie-

${ }^{57}$ Fisher, 1981. Aún está vigente Assadourian, 1982.

${ }^{58}$ Sobre los conflictos en el traspaso de mando, véase Muñoz Cabrera, 1867: 49.

59 Ambos habían sido activos opositores de la rebelión de Túpac Amaru casi veinte años antes. Véase Garrett, 2009: 244.

${ }^{60}$ Sala i Vila, 2018.

${ }^{61}$ Irurozqui, 2011.

62 Soux, 2011a: 58. 
nes se ocuparon de cuidar las espaldas del ejército rioplatense aun después de la derrota de Huaqui ${ }^{63}$. Así cercaron La Paz en agosto de 1811 y, debido a que su asedio no permitía que el ejército realista se organizara, debieron asistirlo las milicias indígenas de Azángaro y Cuzco quienes pacificaron la zona. Esto no sucedió sino hasta mediados de $1812^{64}$. Como resulta evidente, sin la movilización de las comunidades indígenas en uno $\mathrm{u}$ otro bando no es posible entender la dinámica política de las juntas de La Paz y Chuquisaca. Asimismo, los hechos de 1809 ponen de manifiesto la división de la elite indígena entre quienes colaboraron con las autoridades coloniales porque tenían intereses en común y quienes se opusieron de plano a la autoridad española a partir de la ausencia de Fernando VII ${ }^{65}$.

3) Los sectores indigenas tuvieron un rol central en la rebelión de Huánuco y la revolución del Cuzco. La movilización indígena no se circunscribió solo al llamado alto Perú, sino que se extendió a otras áreas del virreinato. Varios historiadores han analizado las conexiones entre la rebelión de Huánuco (1812) y la de Tacna (1811) con los movimientos insurreccionales en el alto Perú ${ }^{66}$. En el caso del Cuzco, aunque la revolución de 1814 puso de manifiesto una convergencia de intereses ideológicos y prácticos particulares, la participación de los sectores indígenas fue central en su desarro$10^{67}$. Específicamente, la insurgencia en algunos partidos de la intendencia de Cuzco y de Puno (Paucartambo, Canas y Canchis, Carabaya y Azángaro) emergió de los indios del común y se distanció claramente de los objetivos y la dinámica impuesta por los lideres tanto indígenas como criollos en la ciudad $^{68}$. En este sentido, la rebelión indígena en el caso de Cuzco puso de manifiesto la crisis generalizada de la estructura de poder comunal que los historiadores han encontrado tanto en el alto Perú como en Charcas. De hecho, Luis Miguel Glave ha postulado que esta revolución alumbró una nueva cultura política, la cual transformó radicalmente las relaciones entre

63 Soux, 2011b: 463.

${ }^{64}$ Roca, 2007.

${ }^{65}$ Es imposible resumir aquí la extensa historiografía sobre los movimientos juntistas entre 1809-1811. Véase Arnade, 1964. Arze Aguirre, 1979. Ballivián de Romero, 1993. Just Lleó, 1994. Demélas, 2007. Soux, 2009. De Mamán, 2010.

${ }_{66}$ Klassen 2016, muestra bien estas conexiones. También véase Chassin, 2008. Bazán Díaz, 2017. Zavala Córdova, 2017. Sobre la revolución del Cuzco, véase Ojeda Escalante, 2016. Una postura comparativa en Fisher, 1979. Peralta Ruíz, 2012.

67 Sobre esta revolución lo más reciente es Ojeda Escalante, 2016 y O’Phelan Godoy, 2016. Véase también Fisher, 1979: 232-257. O’Phelan Godoy, 1987. Cahill y O’Phelan Godoy, 1992. Peralta Ruíz, 1996.

${ }^{68}$ Cahill y O’Phelan Godoy, 1992: 139, 159. 
la corona y sus súbditos americanos ${ }^{69}$. Más allá de la fluctuante interacción con sectores criollos y mestizos, la persistencia de una población indígena movilizada y en armas efectivamente indica que existía una agenda política propia $^{70}$. Por ello, a pesar de la eventual derrota del movimiento cuzqueño y el repliegue del Ejército Auxiliar la movilización continuó en los valles del alto Perú luego de 1815. Tanto Yamila Vega como Roger Mamani han mostrado la capacidad de organización de las milicias indígenas, su articulación y coordinación con la región de Salta, así como también sus objetivos inmediatos que se centraban fundamentalmente en la supervivencia política de sus comunidades ${ }^{71}$.

4) El impacto de la constitución de Cádiz en las comunidades indígenas. Varios historiadores ya han destacado como la implementación de la constitución de Cádiz representó un momento de cambio crucial en la relación entre las comunidades indígenas y la corona española ${ }^{72}$. Dado que las cortes decidieron que fueran las corporaciones locales las que juraran lealtad a la carta magna para luego elegir a las autoridades locales, las comunidades indígenas se apropiaron de este recurso en forma extendida ${ }^{73}$. Gabriella Chiaramonti y Francisco Núñez entre otros han encontrado varios casos en los que las comunidades indígenas obtuvieron el control de los ayuntamientos vía elecciones para luego utilizar sus atribuciones en función de intereses específicos $^{74}$. Esto no llamaría demasiado la atención si los ayuntamientos hubiesen tenido las mismas atribuciones que los antiguos cabildos de indios, pero la constitución otorgó a los ayuntamientos poderes que estos nunca tuvieron. El uso de estos nuevos poderes permitió a las comunidades implementar cambios tanto en la estructura de poder local como en su relación con la autoridad virreinal.

Para comprender la dimensión de este cambio y el efecto trascendental que tuvo en los pueblos de indios vale un ejemplo concreto para lo cual sirve lo ocurrido en el pueblo de indios de Huacho (Intendencia de Lima) durante el periodo de implementación de la constitución. Fundado en 1571, Huacho era una «republica de indios» desde el punto de vista legal que caía bajo la órbita de la villa de españoles de Huaura situada a solo dos leguas en el rico

${ }^{69}$ Glave, 2015: 64.

70 Maqque, 2015. Soux, 2010, capítulo 5.

${ }^{71}$ Mamani Siñani, 2010.Vega, 2015.

72 Hünefeldt, 1978. Sala i Vila, 1992. Núñez, 2005. Morelli, 2008. Guarisco, 2011. Chiaramonti, 2005; 2012.

73 Guarisco, 2011: 177. Morelli, 2005.

${ }^{74}$ Chiaramonti, 2005: 159-162. Núñez, 2005: 368. 
valle de Chancay ${ }^{75}$. Desde el punto de vista económico, Huacho era un activo centro pesquero y también contaba con una salina cuya sal se comercializaba en todo el valle de Chancay. Asimismo, proliferaban las chacras para el cultivo del maíz y de pan llevar, lo cual fustigaba un intenso comercio intrarregional desde Cerro de Pasco hasta Lima que se complementaba con la producción de las haciendas azucareras ubicadas en los alrededores de Huaura ${ }^{76}$.

Cuando se convocaron las primeras elecciones a fines de 1812, dos españoles resultaron electos alcaldes y esto generó la queja de los miembros del antiguo cabildo de indios quienes denunciaron que no les habían permitido $\operatorname{votar}^{77}$. La situación cambió al año siguiente cuando dos representantes de distintas parcialidades resultaron elegidos alcaldes. En esa oportunidad los vecinos españoles a los que se sumó el cura de la doctrina denunciaron irregularidades en el nombramiento de los alcaldes. La disputa legal entre españoles e indios reveló que las autoridades indígenas no solo habían expropiado tierras a los españoles amparándose en las atribuciones del ayuntamiento, sino que además habían limitado el acceso de estos al comercio de la sal. Las tensiones entre facciones locales en Huacho no eran nuevas, como tampoco lo era la pretensión de comunidades como Huacho de obtener cierta autonomía en el gobierno de sus asuntos locales ${ }^{78}$. Sin embargo, la posibilidad de que una corporación de tipo administrativo como el ayuntamiento asumiera funciones judiciales como la conciliación y la justicia en primera instancia era completamente nueva ${ }^{79}$. Los indios de Huacho se ampararon en la constitución para asumir un nivel de autonomía política sin precedentes que permitió a sus alcaldes rechazar la intervención de Lima y afirmar su derecho a decidir en cuestiones de su jurisdicción ${ }^{80}$. Asimismo, los españoles denunciaron que los alcaldes todo lo decidían en asamblea tras lo cual firmaban las resoluciones con la expresión «la regencia lo manda» que es como se autodenominaban ${ }^{81}$. La referencia permite deducir que los

75 Ipinze, 2005: 104. De acuerdo con Guarisco, 2011: 240, entre 1784 y 1824 al menos el $80 \%$ de la población de Huacho era indígena. Según el censo de 1813 había 129 españoles, 53 pardos libres y 2362 indios. Archivo Arzobispal de Lima, Lima (AAL), Estadística IV.V, 1813.

${ }^{76}$ Flores Galindo, 1991: 36, 89.

77 Biblioteca Nacional del Perú, Lima (en adelante BNP), 20000018795, Expediente sobre los autos criminales seguidos entre el subteniente de milicias, Pedro Ruíz y el alcalde constitucional Baltasar Manrique, del pueblo de Huacho, 1814.

${ }^{78}$ Para el caso de Huacho, véase Rosado Loarte, 2014. Una visión más amplia en Premo y Yannakakis, 2019.

79 Garriga y Lorente, 2007. Sala i Vila, 2012: 446.

${ }^{80}$ Morelli, 2005; 2008.

81 BNP, 20000018795. 
indios de Huacho estaban al tanto de la vacatio regis y sabían cómo hacer uso de sus derechos políticos en este contexto.

Dado que la constitución de Cádiz respetó no solo el pluralismo legal del imperio español sino también su naturaleza corporativa, su aplicación funcionó como una oportunidad ideal pata que ciertas comunidades indígenas consolidaran un nivel de autogobierno deseado, pero no siempre alcanzado. El caso de Huacho muestra que el cambio legal también favoreció alteraciones en el liderazgo de las comunidades y nuevos alineamientos políticos a nivel local. A pesar de que la constitución fue abolida en 1814 estos cambios persistieron ya que no solo los cabildos se multiplicaron luego de 1814 sino que además las autoridades locales resistieron la pérdida de atribuciones concedidas por la constitución ${ }^{82}$. En el caso específico de Huacho, las autoridades resistieron el pago de tributos y diezmos entre 1815 y 1818 y continuaron utilizando el lenguaje de Cádiz para defender su derecho a decidir en el ámbito de su jurisdicción como se verá más adelante ${ }^{83}$.

Si bien la aplicación de la constitución de Cádiz no fue pareja en todo el virreinato, numerosas comunidades se apropiaron de las atribuciones concedidas por ella. En estos casos es posible afirmar siguiendo a Antonio Annino, que su implementación introdujo nuevas reglas de juego las cuales alteraron el balance entre territorio y soberanía que había existido hasta entonces ${ }^{84}$. Aquellos pueblos que tomaron el control de la justicia y la administración de tierras consolidaron su soberanía territorial de hecho poniendo de manifiesto el resquebrajamiento de la autoridad imperial tanto simbólica como práctica. Si bien más estudios de caso resultan necesarios, el estado de la cuestión muestra que el impacto de la constitución de Cádiz en las comunidades indígenas fue indudable y sus efectos más perdurables de lo que se ha entendido hasta ahora.

5) Las guerrillas constituyeron la expresión política de la movilización indígena. La historiografía peruana ha prestado atención a la formación de guerrillas y montoneras durante la guerra de independencia del Perú. Sin embargo, el análisis ha privilegiado una postura nacionalista (las guerrillas como expresión del patriotismo indígena) y además se ha circunscripto úni-

${ }^{82}$ Un ejemplo es el pueblo de Casma (Partido de Chancay y Santa, Intendencia de Lima) en Archivo General de la Nación, Lima, Perú (en adelante AGNP), GO BI1 L.55 c. 1019, 1816.

83 BNP, 20000019168, Acta suscrita por los vecinos de Huacho, para acordar la manera de contribuir al sostenimiento del erario real, 1817 y BNP, 20000013352, Expediente sobre la causa seguida a Don José de San Martín, subdelegado de Chancay, por el incumplimiento de la entrega de cantidad de pesos correspondiente a la contribución de indios. AGNP, GO BI 2 L.89 C.676 ff. 99, José del Ribero informa que indios se resisten a pagar contribución.

${ }^{84}$ Annino, 1995. 
camente a la sierra central. La propuesta aquí es incluir en el análisis del proceso de independencia a la actividad guerrillera en los valles del alto Perú. Al hacerlo, se pone de manifiesto que la guerrilla fue una práctica extendida en el espacio andino a partir de las primeras milicias indígenas que se movilizaron en apoyo a las juntas en 1810 y siguiendo con la coalición altiplánicacochabambina-rioplatense que persistió hasta 1812. Varios «caudillos insurgentes» como Baltazar Cárdenas y José Miguel Lanza utilizaron sus milicias indígenas en forma de guerrillas, disponiéndolas tácticamente en el terreno de tal manera que asediaran y provocaran al ejército regular sin entrar en confrontación directa ${ }^{85}$. A pesar de sucesivas derrotas, estas guerrillas continuaron hostigando aisladamente a las comunidades que habían jurado fidelidad a la Corona, mientras ocupaban los caminos cual bandoleros dificultando así el movimiento del ejército realista ${ }^{86}$. El hostigamiento procuró sumar adeptos a la causa insurgente, a la par que recaudaron fondos (a través del robo del tributo indígena) para sostener la rebelión mientras esperaban la segunda venida del ejército auxiliar, esta vez a cargo de Manuel Belgrano. Por ello, Yamila Vega ha afirmado que para 1813 existía en el alto Perú un sistema de guerrillas promovido por realistas y porteños y sostenido (a la vez que padecido) por los pueblos de la zona ${ }^{87}$. Luego de la revolución del Cuzco, la actividad guerrillera continuó en los valles entre La Paz y Cochabamba.

Algunos autores, siguiendo a Bartolomé Mitre, han denominado a esta última guerrilla «republiqueta», minimizando por un lado el grado de organización que tuvo y por el otro presentándola como el momento inaugural de la anarquía político-militar que reinaría durante el siglo XIX ${ }^{88}$. Sin embargo, estudios recientes han demostrado que ésta no solo tenía una organización sofisticada denominada «división de los valles», sino que además se consideraba parte del ejercito rioplatense cuyo nexo era Martín Miguel de Güemes ${ }^{89}$. Esto indica que tenía objetivos de largo alcance además de los coyunturales, y que estaba profundamente integrada en el escenario político continental. De

${ }^{85} \mathrm{La}$ guerrilla no era nueva, era una táctica de guerra que llevaba no cientos, sino miles de años siendo usada. Lo nuevo fue la utilización de esta táctica por parte de los ejércitos regulares en América y el hecho de que estas guerrillas fueran en su mayoría de origen indígena. Sobre la historia de la guerrilla, véase Asprey, 1994, vol. 1, capítulo 7. Sobre los caudillos, véase Paz, 1919, vol. II: 236.

${ }^{86} \mathrm{La}$ expresión proviene de los documentos de época. Soux, 2011b: 465. Los límites entre guerrilla y bandolerismo son forzosamente difusos ya que el pillaje (muchas veces para asegurar la subsistencia) era práctica corriente de la guerra. Véase Fradkin, 2005.

87 Vega, 2015: 8.

${ }^{88}$ El más claro ejemplo en Arnade, 1964.

89 Mata de López, 2004. Demélas, 2007. Mamani Siñani, 2010. 
este modo, su presencia y acciones tenían una influencia en el accionar de los actores regionales, quienes a su vez incidían en el destino de la división.

Desde este punto de vista es posible afirmar que durante la década de 1810 la organización de guerrillas era una práctica extendida y aceptada entre las comunidades indígenas. Su persistencia puede ser explicada a partir de su efectividad para mantener en pie la autonomía de las comunidades en un escenario de guerra. Si bien las guerrillas podían ser derrotadas y desarticuladas como ocurrió en numerosas oportunidades, es posible postular que permitieron un grado de autonomía política a las comunidades que defendían, al que se agregaba aquel garantizado por la constitución de Cádiz. Este proceso se profundizaría con la llegada del ejército libertador en 1820 dado que José de San Martín favoreció e impulsó la organización de milicias locales que debían utilizar la táctica de guerrilla ${ }^{90}$. Como ya ha sido señalado en otro lado, la organización de patrullas, guerrillas y/o montoneras en la sierra central obedeció a la necesidad de conservar el orden interno que la corona ya no garantizaba, así como también defenderse de un enemigo externo cuyas intenciones eran poco claras. Por ello más allá de los incentivos materiales que el ejército libertador otorgó en forma de armas, provisiones y apoyo logístico fueron las propias comunidades quienes comenzaron a organizar partidas de hombres que «se levantaron en armas» y tomaron el control de sus pueblos ${ }^{91}$. Si bien la articulación con el ejercito fue relevante durante el tiempo del protectorado, tanto durante el periodo inicial (1820-1822) como en la etapa posterior se hizo evidente que estas guerrillas/milicias locales perseguían intereses específicos. Puntualmente, dado que la relación con el ejército realista fue más coercitiva que negociada, las comunidades que organizaron guerrillas realistas lo hicieron porque no tuvieron más remedio y porque se hallaban en estado de sitio con su territorio dominado por la presencia del ejército regu$\operatorname{lar}^{92}$. Por el contrario, las comunidades que establecieron relaciones con el ejército libertador mostraron desde un principio que perseguían en primera instancia la defensa de su territorio. Por ello no siempre se mostraron dispues-

${ }^{90}$ La referencia en Comisión nacional del Sesquicentenario..., 1971-1976, tomo VI, volumen 1, doc. 159: 186-187 (4/1/1821).

${ }_{91}$ Escanilla Huerta, 2018.

92 Numerosos ejemplos en Comisión Nacional del Sesquicentenario..., 1971-1976, tomo V, vol. 2, doc. 730: 210 (04/06/1822); vol. 1, doc. 380: 394 (10/10/1821); vol. 5, doc. 1929: 6 (01/06/1823); tomo V, vol. 2, doc. 730: 210 (04/06/1822); vol. 1, doc. 380: 394 (10/10/1821); y vol. 5, doc. 1929: $6(01 / 06 / 1823)$. 
tas a movilizar sus guerrillas/milicias para cumplir con órdenes emanadas del ejército regular ${ }^{93}$.

Estas guerrillas no solo se resistían a ser movilizadas fuera del área geográfica de sus pueblos, sino que además postulaban su derecho a organizarse militarmente con independencia de los intereses del ejército libertador y con comandantes elegidos por las comunidades mismas. Los casos de Supe, Barranca y Pativilca entre otros muestran que como mínimo, la guerra abrió la posibilidad a algunas comunidades de asumir el control político de sus asuntos militares ${ }^{94}$. Dicho de otra forma, estas comunidades demandaron el ejercicio de una soberanía territorial de hecho. Nuevamente se presenta aquí el ejemplo del pueblo de indios de Huacho, cuyos habitantes jugaron un rol central en el abastecimiento del ejército libertador en 1821 así como también en la colaboración militar que prestaron con la organización de milicias locales. En la puja por el poder político local ocurrida en 1822, estos vecinos utilizaron el lenguaje de Cádiz para limitar la injerencia de Lima en asuntos locales. Asimismo, esgrimieron su fidelidad a la causa patriota para reforzar su derecho no solo a la autonomía política sino también a la autoridad territoria ${ }^{95}$. De esta forma, no solo eliminaron la jerarquía de autoridad que hacía que Lima tuviera ascendente sobre otras ciudades de la extinta intendencia, además, afirmaron la soberanía sobre su territorio. La capacidad de los vecinos de Huacho para imponer su voluntad en el ámbito de su jurisdicción es una muestra clara de que esta pretendida autonomía fue no solo un objetivo sino más bien una realidad en medio de la guerra.

\section{Conclusiones}

Este panorama conduce a una serie de conclusiones respecto del rol que los sectores indígenas jugaron en el proceso de independencia. Por un lado, resulta evidente que la movilización política de las comunidades indígenas no se detuvo con la derrota de la rebelión de Túpac Amaru. Persistió allí en donde fue posible desafiar el poder de los funcionarios de la corona para lograr concesiones políticas concretas como la elección de alcaldes y recaudadores de tributos. Por otro lado, es innegable que la crisis imperial abrió la puerta a procesos de cambio político en América hispana que no fueron posibles en

93 Véanse las quejas de Francisco de Paula Otero al respecto, Comisión nacional del Sesquicentenario..., 1971-1976, tomo V, vol. 1, doc. 114:149 (17/12/1820).

${ }_{94}$ Los ejemplos citados, en BNP, D.12626, 1823.

${ }_{95} \mathrm{He}$ analizado este caso en Escanilla Huerta, 2014. 
las décadas previas. Sin embargo, es posible postular que la vacatio regis no generó simplemente una respuesta, sino que por el contrario los sectores indígenas vieron en ella una oportunidad para avanzar intereses locales específicos que en general se relacionaron con mayores cuotas de autogobierno local. En ese contexto, la persistencia de la guerra creó un espacio para el desarrollo de nuevas formas de hacer política que pudieran cumplir con este objetivo. Entonces, el hecho de que distintas comunidades en diferentes momentos durante la década de 1810 echaran mano de la guerrilla no es una coincidencia, sino que marca una tendencia en la cual los sectores indígenas privilegiaron una táctica que permitía un nivel de autonomía política en el corto plazo. Si a ello le sumamos el efecto que la implementación de la constitución de Cádiz tuvo en el gobierno de las comunidades, es imposible concluir que los sectores indígenas presenciaron «silenciosos» y/o «pasivos» el drama de la independencia. No solo los ejércitos regulares no habrían sobrevivido sin el apoyo logístico de las comunidades a lo largo del virreinato, sino que el accionar de las guerrillas en el contexto de la guerra puso de manifiesto un fenómeno de construcción de soberanía a nivel local que se produjo en paralelo a la guerra y que se consolidó con ella. Por otra parte, tampoco es posible referirse al patriotismo de las comunidades a menos que por patria se entienda la patria local. De todas formas, el hecho de que las comunidades indígenas defendieran intereses eminentemente locales no implica que no buscaran un cambio radical en la relación que tenían con la corona española. Entender en qué consistía este cambio es mucho más complejo, aunque se pueden esbozar algunas ideas.

Como se ha dicho, los estudios disponibles no permiten hacer mayores generalizaciones que las ya formuladas aquí. Es necesario profundizar en cada uno de los postulados descriptos para poder entender mejor las motivaciones de los sectores indígenas para colaborar u oponerse a los diversos actores que habitaron el espacio virreinal peruano.

De todas formas, cuando se contempla su participación determinante en el proceso independentista, resulta claro que la narrativa existente necesita ser modificada en al menos dos aspectos. En primer lugar, es necesario cambiar la geografía del proceso para incluir lo acontecido en el alto Perú porque fue un escenario fundamental del proceso independentista que afectó a todo el virreinato (tal como los sucesos de Quito) más allá de que no acabara formando parte del Perú republicano al final del proceso. Las conexiones tanto económicas como políticas y culturales entre el alto y el bajo Perú deben ser exploradas en profundidad para poder comprender con mayor detalle la articulación de espacios de resistencia a la autoridad española en toda la región, así como también aquellos focos de apoyo realista. De la misma manera, es 
necesario alterar la cronología de la guerra porque como se ha visto, la movilización indígena ocurrió en todo el sur andino y no comenzó en 1820 sino que se remonta a $1809^{96}$.

En segundo lugar, si bien en esta instancia no es posible afirmar que existió un proyecto político indígena, si se puede hacer una inferencia: los intereses particulares de cada comunidad (o grupo de comunidades en algunos casos) primaron a la hora de tomar decisiones políticas. Aquellas comunidades que se alinearon con la corona negociaron los términos de su obediencia y obtuvieron (o aspiraron a obtener) reducciones impositivas o beneficios materiales específicos a cambio de su lealtad ${ }^{97}$. Aquellas que se opusieron a la autoridad colonial recurrieron a las milicias indígenas para mantener su autonomía y defender el territorio de la comunidad. Por ello, la presencia y persistencia de las guerrillas indígenas a lo largo de este periodo permite plantear que la guerrilla no fue simplemente una táctica de combate, sino que constituyó una forma de hacer política ${ }^{98}$. Las comunidades indígenas recurrieron a ella una y otra vez a lo largo de la década de 1810 porque, aunque no fuera efectiva más que en el corto plazo, la guerrilla servía a sus intereses particulares y coyunturales cuando estos se hallaban amenazados. Dado que la guerrilla persistió como forma de hacer política a lo largo del siglo XIX se abre la incógnita de qué papel concreto jugó en la construcción del Perú republicano. Aun cuando esta pregunta no puede ser contestada en este contexto, si se puede plantear que este tema merece ser analizado para comprender mejor como se articuló el Perú del siglo XIX.

Para finalizar, vale una comparación con el caso mexicano. La formulación de una visión indígena de la independencia no incluiría una postura parroquial tal como la definiera Eric Van Young para los sectores indígenas en México ${ }^{99}$. En el caso del Perú no habría existido campanillismo porque si bien los sectores indígenas persiguieron una soberanía de naturaleza descentralizada, cuyas características fueron el auto gobierno y la autonomía jurisdiccional, también organizaron articulaciones regionales en particular en el sur del virreinato tanto durante la década de 1810 como luego de la independencia. Estas articulaciones fueron efímeras, pero presentaron desafíos concretos a la autoridad española y al naciente estado republicano en

${ }^{96}$ La cronología de la guerra más aceptada es la de Guardino, 1989, que luego fue comentada y ampliada por Fonseca Ariza, 2010. La propuesta más reciente es Escanilla Huerta, 2018.

${ }_{97}$ Por ejemplo, acceso al fuero militar. Véase Sobrevilla Perea, 2010. Ricketts, 2012: 426-428.

${ }_{98}$ Me apoyo en el aparato teórico desarrollado por Rabinovich, 2013.

99 Van Young, 2001. 
años posteriores. En el mismo sentido, si se acepta que la guerrilla constituyó una expresión política de la movilización indígena, la independencia ya no sería solo ese momento de quiebre inevitable luego de años de contrarrevolución y resistencia de las elites regionales a los diversos proyectos separatistas. La independencia también sería el laboratorio donde los sectores indígenas alumbraron nuevas formas de hacer política que perduraron en el periodo siguiente dado que las guerrillas continuaron presentes durante todo el siglo XIX. En este sentido, los sectores indígenas no fueron simples espectadores del proceso de construcción del estado peruano sino protagonistas de este proceso. Qué proyectos apoyaron, de qué formas y con qué objetivos lo hicieron en el Perú posterior a 1824 son cuestiones que merecen ser analizadas ya que no han recibido atención por parte de la historiografía reciente. De la misma manera, cualquier análisis de las formas de hacer política en el espacio andino peruano debe necesariamente incluir un análisis de las guerrillas/milicias locales indígenas si se quiere comprender la dinámica política en el temprano Perú republicano.

\section{BiBLIOGRAFÍA}

Adanaqué Velásquez, Raúl, "Cerro de Pasco en el proceso de la independencia (18191824)", Investigaciones sociales, 14/25 (Lima, 2010): 105-140.

Aguirre, Carlos, "La segunda liberación? El nacionalismo militar y la conmemoración del sesquicentenario de la independencia peruana", Carlos Aguirre y Paulo Drinot (eds.), La revolución peculiar. Repensando el gobierno militar de Velasco, Lima, IEP, 2018: 41-70.

Anna, Timothy, La caída del gobierno español en el Perú. El dilema de la independencia, Lima, IEP, 2003.

Annino, Antonio, "Cádiz y la revolución territorial de los pueblos mexicanos, 18121821", Antonio Annino (ed.), Historia de las elecciones en Iberoamérica, siglo XIX, Buenos Aires, Fondo de Cultura Económica, 1995: 177-226.

Arnade, Charles, La dramática insurgencia de Bolivia. La Paz, Librería Juventud, 1964.

Arze Aguirre, René, Participación popular en la independencia de Bolivia, La Paz, Librería Juventud, 1979.

Asprey, Robert P., War in the Shadows: The Guerrilla in History, Lincoln, Nebraska, Guild, 1994.

Assadourian, Carlos Sempat, El sistema de la economía colonial. Mercado interno, regiones y espacio económico, Lima, IEP, 1982. 
Ballivián de Romero, Florencia, "Los primeros levantamientos en Charcas", Los bolivianos en el tiempo, La Paz, Universidad Andina Simón Bolívar/INDEAA, 1993: 176-184.

Basadre, Jorge, La multitud, la ciudad y el campo en la historia del Perú, Lima, Imprenta A. J. Rivas Berrio, 1929.

Basadre, Jorge, La iniciación de la república. Contribución al estudio de la revolución politica y social del Perú, Lima, Librería Francesa científica, 1929-1930.

Basadre, Jorge, El azar en la historia y sus límites, Lima, P. L. Villanueva, 1973.

Bazán Díaz, Marissa, La participación de los sectores populares en la rebelión de Huánuco, 1812: saqueadores, seductores e incanistas, tesis de maestría, Lima, Universidad Nacional Mayor de San Marcos, 2017.

Beltrán Gallardo, Ezequiel, Las guerrillas de Yauyos en la emancipación del Perú, 1820-1824, Lima, Editores Técnicos Asociados, 1977.

Bonilla, Heraclio, Metáfora y realidad de la Independencia en el Perú, Lima, IEP, 2001.

Bonilla, Heraclio y Spalding, Karen, "La Independencia en el Perú: las palabras y los hechos", Heraclio Bonilla (ed.), La independencia en el Perú, Lima, IEP/ Ediciones Campodónico, 1972: 15-64.

Caceres-Olazo Monroy, Jorge Mariano, Los campesinos del altiplano Q'ollavino en los movimientos contra el orden colonial hispánico (1800-1826), San Miguel, Perú, Universidad Nacional Federico Villarreal, 1999. Cuadernos de Investigación serie Antropología, 1.

Cahill, David, "Curas and Social Conflict in the Doctrinas of Cuzco, 1780-1814", Journal of Latin American Studies, 16/2 (Londres, 1984): 241-276.

Cahill, David y O'Phelan Godoy, Scarlett, "Forging Their Own History. Indian Insurgency in the Southern Peruvian Sierra, 1815", Bulletin of Latin American Research, 11/2 (Londres, 1992): 125-167.

Chassin, Joelle, "El rol de los alcaldes de indios en las insurrecciones andinas", $B u$ lletin de l'Institut Français d'Études Andines, 37/1 (Lima, 2008): 227-242.

Chiaramonte, Jose Carlos, "Modificaciones del pacto imperial", Antonio Annino y François-Xavier Guerra (coords.), Inventando la nación. Iberoamérica siglo XIX, Madrid, FCE, 2003: 85-116.

Chiaramonti, Gabriella, Ciudadanía y representación en el Perú (1808-1860), Lima, Fondo editorial de la Universidad Nacional Mayor de San Marcos/ONPE, 2005.

Chiaramonti, Gabriella, "Ensayando nuevos derechos: elecciones gaditanas en los pueblos del Perú", Carmen McEvoy, Mauricio Novoa y Elías Palti (eds.), En el nudo del imperio. Independencia y democracia en el Perú, Lima, IFEA/IEP, 2012: 315-342. 
Comisión del Bicentenario de la Rebelión Emancipadora de Tupac Amaru, Colección documental del bicentenario de la revolución emancipadora de Túpac Amaru, Lima, Comisión del Bicentenario de la Rebelión Emancipadora de Tupac/Amaru, 1980.

Comisión nacional del Sesquicentenario de la independencia, Colección Documental de la Independencia del Perú, Lima, Comisión nacional del Sesquicentenario de la independencia, 1971-1976, 86 vols.

Contreras, Carlos, "La independencia del Perú. Balance de la historiografía contemporánea", Manuel Chust y José Serrano (eds.), Debates sobre las independencias iberoamericanas, Madrid, AHILA/Iberoamericana, 2007: 99-118.

De la Puente Candamo, José Agustín, Notas sobre la causa de la independencia del Perú, Lima, Villanueva, 1971.

De Mamán, Itala, "Participación indígena en la independencia altoperuana: la región de Cochabamba", Heraclio Bonilla (ed.), Indios, negros y mestizos en la independencia, Bogotá, Planeta, 2010: 216-233.

Demélas, Marie-Danielle, Nacimiento de la guerra de guerrilla. El diario de José Santos Vargas (1810-1825), La Paz, IFEA/Plural Editores, 2007.

Di Meglio, Gabriel, “La participación popular en las revoluciones hispanoamericanas 1808-1816. Un ensayo sobre sus rasgos y causas", Almanack, Garulhos, 05 (São Paulo, 2013): 97-122

Díaz, Mónica (ed.), To Be Indio in Colonial Spanish America, Albuquerque, New Mexico Press, 2017.

Earle, Rebecca, The Return of the Native. Indians and Myth-Making in Spanish America, 1810-1930, Durham, NC/Londres, Duke University Press, 2008.

Escanilla Huerta, Silvia, El quiebre del orden establecido: movilización social, inestabilidad política y guerra en la costa central del Perú, 1816-1822, tesis de maestría, Universidad de San Andrés, 2014.

Escanilla Huerta, Silvia, "Hacia una nueva cronología de la guerra de independencia en el Perú", Carmen McEvoy y Alejandro Rabinovich (eds.), Tiempo de guerra: Estado, nación y conflicto armado en el Perú, siglos XVII-XIX, Lima, IEP, 2018: 111-138.

Espinoza Soriano, Waldermar, "Reacción de los indígenas de Cajamarca frente a la independencia de Trujillo y Lima, 1821-1822”, Investigaciones Sociales, 11/18 (Lima, 2007): 179-220.

Fisher, John, "Royalism, Regionalism and Rebellion in Colonial Peru, 1808-1815", Hispanic American Historical Review, 59/2 (Durham, May 1979): 232-257.

Fisher, John, Gobierno y sociedad en el Perú colonial. El régimen de las intendencias, Lima, PUCP. 1981. 
Fisher, John, El Perú borbónico 1750-1824, Lima, IEP, 2000.

Flores Galindo, Alberto, La ciudad sumergida. Aristocracia y plebe en Lima, 1760 1820, Lima, Editorial Horizonte, 1991. (Segunda edición).

Fonseca Ariza, Juan, “BBandoleros o patriotas? Las guerrillas y la dinámica popular en la independencia del Perú”, Histórica, XXXIV/1 (Lima, 2010): 106-128.

Fradkin, Raul, "Bandolerismo y politización de la población rural de Buenos Aires tras la crisis de la Independencia (1815-1830)", Nuevos Mundos, Mundos Nuevos, [en línea], Debates, puesto en línea el 22 febrero 2005, consultado el 10 febrero 2021, URL: http://journals.openedition.org/nuevomundo/309; DOI: https://doi. org/10.4000/nuevomundo.309

Garrett, David, Sombras del imperio. La nobleza indigena del Cuzco, 1750-1825, Lima, IEP, 2009.

Garriga, Carlos y Lorente, Marta (eds.), Cádiz 1812. La constitución jurisdiccional, Madrid, CEPC, 2007.

Ginzburg, Carlo, Mitos, emblemas e indicios. Morfología e Historia, Madrid, Gedisa, 1999.

Glave, Luis Miguel, "Un héroe fragmentado. El cura Muñecas y la historiografía andina”, Andes, 13 (2002) Redalyc, https://www.redalyc.org/articulo.oa?id=12701303

Glave, Luis Miguel, "Las otras rebeliones. Cultura popular e independencia e independencias", Anuario de Estudios Americanos, 62/1 (Sevilla, 2005): 275-312.

Glave, Luis Miguel, "Guerra, política y cultura en la génesis de la independencia andina, 1808-1815” Nueva Corónica, 2 (Lima, Julio 2013): 189-230.

Glave, Luis Miguel, "El Cusco de 1814. Laboratorio de una nueva cultura política. Estudio introductorio", Carlos Contreras y Luis Miguel Glave (eds.) La independencia del Perú. ¿Concedida, conseguida, concebida?, Lima, IEP, 2015: 9-36.

Guarisco, Claudia, La Reconstitución del espacio político indígena. Lima y el valle de México durante la crisis de la monarquía española, Barcelona, Publicacions de la Universitat Jaume I, 2011.

Guardino, Peter, "Las guerrillas y la independencia peruana, un ensayo de interpretación", Pasado y Presente, 2-3 (Lima, 1989): 101-117.

Guerra, François-Xavier, Modernidad e independencias. Ensayos sobre las revoluciones hispánicas, Ciudad de México, Fondo de Cultura Económica, 1993.

Hamnett, Brian, Revolución y contrarrevolución en México y el Perú. Liberalismo, realeza y separatismo (1800-1824), México, FCE, 1978.

Hünefeldt, Christine, “Los indios y la Constitución de 1812”, Allpanchis, XI (Cuzco, 1978): 33-58. 
Hünefeldt, Christine, Lucha por la tierra y protesta indígena. Las comunidades indígenas del Perú entre colonia y republica, 1800-1830, Bonn, Bonner Amerikanische Studien, 1982.

Igue, José Luis, Bandolerismo, patriotismo y etnicidad poscolonial: los "morochucos" de Cangallo, Ayacucho en las guerras de independencia, 1814-1824, tesis de licenciatura, Pontificia Universidad Católica del Perú, 2008.

Ipinze, Jesús Elías, La antigua provincia de Chancay, siglos XVI-XVIII, Huacho, Comisión de celebración del centenario del nacimiento del historiador Jesús Elías Ipinze, 2005.

Ipinze, Jesús Elías, La campaña libertadora del general San Martín en el norte chico, Huacho, Municipalidad provincial de Huaura, 2010.

Irurozqui Victoriano, Marta, "Soberanía y castigo en Charcas. La represión militar y judicial de las juntas de La Plata y La Paz, 1808-1810", Revista Complutense de Historia de América, 37 (Madrid, 2011): 49-72

Just Lleó, Estanislao, Comienzo de la independencia en el Alto Perú: los sucesos de Chuquisaca, 1809, Sucre, Editorial Judicial, 1994.

Klassen, David, The Unraveling Colonial Order: Tribute and Indigenous Politics in the Southern Peruvian Andes from the Tupac Amaru Rebellion to Independence (1781-1824), PhD Dissertation, New York, NYU University, 2016.

Lynch, John, Las revoluciones hispanoamericanas, Barcelona, Ariel, 1980.

Mamani Siñani, Roger, "La división de los valles": estructura militar, social y étnica de la guerrilla de la Paz y Cochabamba (1814-1817), La Paz, Instituto de Estudios Bolivianos, 2010.

Maqque, Víctor, "En mi voz y de todo el común: base de la cultura política en el Altiplano tardo-colonial", Antropología Andina Muhunchik-Jathasa, 2/2 (Puno, 2015): 50-63.

Marchena Fernández, Juan, "La insurgencia indígena en el proceso de la lucha por la independencia en la región andina: un asunto aún sin ubicar en la agenda del bicentenario", Manuel Chust y Claudia Rosas (eds.), El Perú en revolución. Independencia y guerra: un proceso, 1780-1826, Castellón de la Plana, Fondo Editorial PUCP/Universitat Jaume I/El Colegio de Michoacán, 2017: 27-60.

Mata de López, Sara, "Salta y la guerra de Independencia en los Andes meridionales", Jahrbuch für Geschichte Lateinamerikas, 41 (Hamburgo, 2004): 223-246.

Mazzeo de Vivó, Cristina, "Pagando por la guerra: comercio y finanzas. Entre la independencia y la Guerra de la Confederación", Carmen McEvoy y Alejandro Rabinovich (eds.), Tiempo de guerra. Estado, nación y conflicto armado en el Perú, siglos XVII-XIX, Lima, IEP, 2018: 191-214. 
Méndez, Cecilia, La Republica plebeya. Huanta, formación del estado peruano 1820-1850, Lima, IEP, 2014. (Primera edición 2005).

Mendoza Villanueva, Pío, Pasco en la guerra de la independencia, Lima, Fondo Editorial Industrias Nieto, 2012.

Morán, Daniel, "La historiografía de la revolución. La participación plebeya durante las guerras de independencia en el Perú y el Río de la Plata", Nuevo Mundo Mundos Nuevos (2011), [en línea], URL: http://nuevomundo.revues.org/61404

Morelli, Federica, Territorio o Nación. Reforma y disolución del espacio imperial en Ecuador, 1765-1830, Madrid, Centro de Estudios Políticos y Constitucionales, 2005.

Morelli, Federica, "Pueblos, alcaldes y municipios: la justicia local en el mundo hispánico entre Antiguo Régimen y Liberalismo", Historia Crítica, 36 (Bogotá, 2008): 36-57.

Muñoz Cabrera, Juan Ramón, La guerra de los 15 años en el Alto Perú, Santiago, Imprenta Independiente, 1867.

Najarro, Margareth, "Los veinticuatro electores incas y los movimientos sociales y políticos. Cusco: 1780-1814", Manuel Chust y Claudia Rosas Lauro (eds.), El Perú en revolución. Independencia y guerra: un proceso, 1780-1826, Castellón de la Plana, Publicacions de la Universitat Jaume I, 2017: 113-130.

Nuñez, Francisco, "La participación electoral indígena bajo la Constitución de Cádiz (1812-1814)", Cristobal Aljovín de Losada y Sinesio López (eds.), Historia de las elecciones en el Perú. Estudios sobre el gobierno representativo, Lima, IEP, 2005: 361-394.

Ojeda Escalante, Roberto y Colectivo por el Bicentenario de la Revolución del Cusco, El cusco insurrecto: la revolución de 1814 doscientos años después, Cusco, Ministerio de Cultura, 2016.

O'Phelan Godoy, Scarlett, "El mito de la independencia concedida, los programas políticos del siglo XVIII y del temprano XIX en el Perú y el Alto Perú (17801840)", Alberto Flores Galindo (ed.), Independencia y Revolución (1780-1840), Lima, Instituto Nacional de Cultura, 1987, tomo 2: 145-199.

O'Phelan Godoy, Scarlett, Un siglo de rebeliones anticoloniales. Perú y Bolivia 17001783, Cuzco, Centro Bartolomé de las Casas, 1988.

O'Phelan Godoy, Scarlett, Kurakas sin sucesiones. Del cacique al alcalde de indios. Perú y Bolivia 1750-1835, Cuzco, Centro Bartolomé de las Casas, 1997.

O'Phelan Godoy, Scarlett, "Una inclusión condicional: indios nobles, indios del común, esclavos y castas de color entre la rebelión de Túpac Amaru y la independencia", Beatriz Bragoni y Sara Mata (comp.), Entre la colonia y la república. Insurgencias, rebeliones y cultura política en América del Sur, Buenos Aires, Prometeo, 2009: 75-94. 
O'Phelan Godoy, Scarlett (ed.), 1814: La junta de gobierno del Cuzco y el sur andino, Lima, IFEA, 2016.

O’Phelan Godoy, Scarlett y Lomné, Georges (eds.), Abascal y la contra independencia de América del Sur, Lima, IFEA/PUCP, 2013.

Paz, Luis, Historia General del Alto Perú, hoy Bolivia, La Paz, Imprenta Bolívar, 1919.

Paz Soldán, Mariano Felipe, Historia del Perú independiente, Lima, Alfonso Lemale, 1868.

Peralta Ruíz, Víctor, "Elecciones, constitucionalismo y revolución en el Cusco, 18091815”, Revista de Indias, LVI/206 (Madrid, 1996): 99-131.

Peralta Ruíz, Víctor, En defensa de la autoridad: política y cultura bajo el gobierno del virrey Abascal (Perú 1806-1816), Madrid, Consejo Superior de Investigaciones Científicas, 2002.

Peralta Ruíz, Víctor, "La participación popular en las juntas de gobierno peruanas de Huánuco (1812) y Cuzco (1814)", María del Pilar Cagiao Vila y José María Portillo Valdés (coords.), Entre el Imperio y las Naciones. Iberoamérica y el Caribe en torno a 1810, Santiago de Compostela, Universidad de Santiago de Compostela, 2012: 317-340.

Peralta Ruíz, Víctor, "La revolución de la independencia del Perú (1860) de Benjamín Vicuña Mackenna en la historiografía peruana”, Histórica, XXXVII/1 (Lima, 2013): 109-133.

Premo, Bianca y Yannakakis, Yanna, "A Court of Sticks and Branches: Indian Jurisdiction in Colonial Mexico and Beyond", American Historical Review, 124/Issue 1 (Bloomington, 2019): 28-55.

Pruvonena, P. (José de la Riva Agüero), Memorias y documentos para la historia de la independencia del Perú, y causa del mal éxito que ha tenido ésta, París, Librería de Garnier Hermanos, 1858.

Quijada, Mónica, "Las dos tradiciones. Soberanía popular e imaginarios compartidos en el mundo hispánico en la época de las grandes revoluciones atlánticas", Jaime Rodríguez (coord.), Revolución, independencia y las nuevas naciones de América, Madrid, MAPFRE Tavera, 2005: 61-86.

Rabinovich, Alejandro y Zubizarreta, Ignacio, A modo de introducción: Clausewitz a caballo (o hacia una teoría de la guerra y la política aplicada al Rio de la Plata), Foro La movilización militar y las formas de la política en el espacio rioplatense, 1810-1880, 2013, disponible en línea en http://historiapolitica.com/ foros/movilizacion-militar/

Ricketts, Mónica, "The Rise of the Bourbon Military in Peru, 1768-1820", Colonial Latin American Review, 21/3 (Londres, 2012): 413-439. 
Rivera Serna, Raúl, Los guerrilleros del centro en la emancipación peruana, Lima, P. L. Villanueva, 1958.

Roca, José Luis, Ni con Lima ni con Buenos Aires, La Paz, Plural, 2007.

Roel Pineda, Virgilio, La independencia, Historia general del Perú, Lima, Editorial Gráfica Labor, 1988.

Rosado Loarte, Luis, "Los caciques del pueblo de San Bartolomé de Huacho en el siglo XVIII", Historia y Región, II/2 (Huacho, 2014): 85-104.

Rosado Loarte, Luis, "Infieles al Rey: el pueblo de San Bartolomé de Huacho durante el proceso de independencia, 1812-1822", Luis Rosado Loarte, Guido Riveros y Paulo Lanas (eds.), Narra la independencia desde tu pueblo 1, Lima, IEP, 2017: 59-104.

Rosas Cuadros, Emilio, El prócer Francisco de Vidal y su contribución a la emancipación del Perú, Lima, Editorial Gráfica Industrial, 1971.

Rosas Cuadros, Emilio, La provincia de Chancay entre la colonia y la emancipación, Lima, Editorial Gráfica Industrial, 1976.

Sala i Vila, Nuria, "Mistis e indígenas. La lucha por el control de las comunidades en Lampa, Puno, a fines de la colonia", Boletín Americanista, 41 (Barcelona, 1991): 35-66.

Sala i Vila, Nuria, "La Constitución de Cádiz y su impacto en el gobierno de las comunidades indígenas en el virreinato del Perú", Boletín Americanista, XXXIII/42-43 (Barcelona, 1992-93): 51-70.

Sala i Vila, Nuria, $Y$ se armó el tole tole. Tributo indígena y movimientos sociales en el virreinato del Perú, 1784-1814, Ayacucho, IER José María Arguedas, 1996.

Sala i Vila, Nuria, "Justicia conciliatoria durante el liberalismo hispano en el Perú: el caso de Huamanga", Anuario de Estudios Americanos, 9/2 (Sevilla, 2012): 343-382.

Sala i Vila, Nuria, "Indígena y abogado: el caso de José Domingo Choquehuanca de Azángaro", Histórica, XLII/2 (Lima, 2018): 43-88.

Sánchez Jara, César Christian, "Los sectores populares del norte chico y su participación en la independencia del Perú", Jaime Menacho Carhuanca et. al., Hacia el Bicentenario de la Independencia del Perú 2021, Lima, Ministerio de Educación/ OEA-PUCP, 2010: 59-85.

Serulnikov, Sergio, Conflictos sociales e insurrección en el mundo colonial andino. El norte de Potosí en el siglo XVIII, Buenos Aires, FCE, 2006.

Serulnikov, Sergio, "En torno a los actores, la política y el orden social en la independencia hispanoamericana", Nuevo Mundo Mundos Nuevos [en línea], (2010a), puesto en línea el 18 de mayo de 2010, URL: http://nuevomundo.revues.org/59668

Serulnikov, Sergio, Revolución en los Andes. La era de Túpac Amaru, Buenos Aires, Sudamericana, 2010b. 
Sobrevilla Perea, Natalia, "Hermanos, compañeros y amigos de sus mismos contrarios: las guerras de independencia en el Sur Andino 1805-1825”, Historiapolitica.com (Buenos Aires, 2010) http://historiapolitica.com/datos/biblioteca/sobrevilla.pdf

Sobrevilla Perea, Natalia, "Colored by the past. Identity and the armed forces in Peru, from colonial militias to armies of independence", Estudios Interdisciplinarios de América Latina y el Caribe, 22/1 (Tel Aviv, 2011): 57-79.

Sobrevilla Perea, Natalia, "De vasallos a ciudadanos: Las milicias coloniales y su transformación en un ejército nacional en las guerras de independencia en el Perú", Carmen Mc Evoy, Mauricio Novoa y Elías Palti (eds.), En el nudo del imperio. Independencia y democracia en el Perú, Lima, IEP, 2012: 251-270.

Sobrevilla Perea, Natalia, "La nación subyacente: de la monarquía hispánica al Estado en el Perú", Carlos Contreras y Luis Miguel Glave (eds.), La independencia del Perú. ¿Concedida, conseguida, concebida?, Lima, IEP, 2015: 399-426.

Soux, María Luisa, "Los caudillos insurgentes en la región de Oruro: entre la sublevación indígena y el sistema de guerrillas”, Beatriz Bragoni y Sara Mata (comp.), Entre la Colonia y la República. Insurgencias, rebeliones y cultura política en América del Sur, Buenos Aires, Prometeo Libros, 2009: 125-142.

Soux, María Luisa, El complejo proceso hacia la independencia de Charcas: Guerra, ciudadanía, conflictos locales y participación indígena en Oruro, La Paz, Plural, 2010 .

Soux, María Luisa "Insurgencia y Alianza: Estrategias de la participación indígena en el proceso de Independencia en Charcas. 1809-1812”, Studia Historica. Historia Contemporánea, 11 (2011a): 53-74.

Soux, María Luisa, "Rebelión, guerra y tributo: los indios en Charcas durante el proceso de independencia", Anuario de Estudios Americanos, 68/2 (2011b): 455482.

Thomson, Sinclair, We Alone will Rule. Native Andean Politics in the Age of Insurgency, Madison, The University of Wisconsin Press, 2002.

Torrente, Mariano, Historia de la revolución hispanoamericana, Madrid, Imprenta de don León Amarita, 1829.

Van Young, Eric, La otra rebelión. La lucha por la independencia de México, 1810 1821, Ciudad de México, Fondo de Cultura Económica, 2001.

Vargas Ezquerra, Juan Ignacio, Un hombre contra un continente. José Fernando de Abascal, rey de América (1806-1816), León, Editorial Akrón, 2010.

Vargas Ugarte, Rubén, Historia del Perú: Emancipación, 1809-1825 (Vol. 5), Buenos Aires, Imprenta López, 1958. 
Vega, Yamila, "Guerras de independencia, acciones colectivas y movilización de los sectores subalternos. Las Guerrillas Insurgentes de Cochabamba (1813-1816)", Surandino Monográfico, 4 (Buenos Aires, 2015): 1-16.

Vergara Arias, Gustavo, Montoneras y guerrillas en la etapa de la emancipación del Perú, 1820-1840, Lima, Editorial Salesiana, 1973.

Walker, Charles, The Tupac Amaru Rebellion, Cambridge, Mass., Harvard University Press, 2014.

Walker, Charles, "El general y su héroe. Juan Velasco Alvarado y la reinvención de Túpac Amaru II", Carlos Aguirre y Paulo Drinot (eds.), La revolución peculiar. Repensando el gobierno militar de Velasco, Lima, IEP, 2018: 71-104.

Zavala Córdova, Gonzalo, “La rebelión de Huánuco en 1812. Aportes historiográficos”, Revista Archivo Regional de Huánuco, $2 / 2$ (Huanuco, 2017): 77-93.

Fecha de recepción: 19 de enero de 2020.

Fecha de aceptación: 31 de agosto de 2020.

\section{The role of indigenous sectors in Peruvian independence. Grounds for a new interpretation}

The role of indigenous peoples in the independence process of the viceroyalty of Peru has never been clear. Some historians have claimed indigenous peoples did not play a major role, while others have referred to a staunch patriotism, in which their loyalty to the independence cause was in stark contrast to the hesitation of the elites, throughout the 1808-1824 period. Since indigenous people accounted for the majority of the population and given that they fought as soldiers in the war, I advocate moving beyond dichotomies and analysing their status as key political players of the period. By focusing on the political strategies adopted by indigenous peoples between the beginning of the monarchical crisis of 1808 and the end of the war in 1824, I will argue that indigenous peoples created a new way of doing politics that would define, and far outlast, the war of independence.

KEY WORDS: indigenous peoples; war of independence; guerrilla; viceroyalty of Peru. 
